\title{
Digital Influencers e o Instagram como instância de legitimação de tendências
}

Digital Influencers and Instagram as an instance of legitimation of fashion trends

GENTIL, Olívia; Mestranda; PUC-Rio

oliviablanc24@gmail.com

CIPINIUK, Alberto; Doutor; PUC-Rio

acipiniuk@gmail.com

ARAGÃO, Irina; Doutora; PUC-Rio

irinaa@uol.com.br

\section{Resumo}

Este artigo visa definir e desmistificar a figura da influenciadora digital de moda e suas complexas operações de poder de comunicação, legitimação, subordinação e dominação, que ocorrem entre a indústria, os consumidores e entre elas mesmas. Ao longo do texto explicaremos o que são as digital influencers e como a noção materialista em oposição à idealista nos ajuda a compreender que estas são engrenagens da indústria de moda, que trabalham para a produção da mais valia e não pessoas que têm gosto mais bem apurado do que as demais.

Especificaremos como ocorre o processo de legitimação no Campo da Moda por intermédio dessas mulheres e dos meios digitais que fazem uso. Oferecemos também exemplos de como o público, seus pares (outras influenciadoras e marcas de moda), a geografia e a imagem fotográfica reforçam sua posição junto à indústria e ao público. Por fim, daremos um parecer de como a comunicação de moda mediada por computadores vem mudando a forma de consumir e expor produtos e de como a propaganda feita por essas mulheres parece ser mais eficaz do que a feita de maneiras convencionais (com modelos pagas, fotografias posadas e expostas em suportes convencionais, como revistas especializadas).

Palavras-Chaves: moda, digital influencer, Instagram e legitimação.

\begin{abstract}
This article aims to comprehend and desmistifie fashion digital influencers and the complex power operations, legitimation, subordination and domination between them, the fashion industry and consumers. Though the text we are going to explain who are digital influencers and how the materialist notion helps us comprehend that they are industry gears, who works for the production of surplus value and not people with better taste than others.

We are going to specify how the process of legitimation occurs and exemplify how the public, other digital influencers and fashion brands, location and photo image reinforce their position with both audience and industry. Lastly, we are going to give an opinion on how the computer-mediated fashion communication changes the way of consuming and how the advertising made by influencers seems more accurate than the ones done in a conventional way (with models and
\end{abstract}


exposed on conventional media, as fashion magazines).

Keywords: fashion, digital influencer, Instagram and legitimation.

\section{Considerações iniciais}

Nos últimos anos, com o advento da internet nota-se que a informação nos chega cada vez mais por meios digitais, no Campo da Moda não é diferente, a cada dia verificamos que nossos gostos são influenciados pelos meios digitais. Um fenômeno que tem chamado atenção, não só de consumidores de internet como também por parte das grandes maisons ${ }^{1}$ são as blogueiras de moda, que hoje migraram para o Instagram ${ }^{2}$ e são denominadas digital influencers. ${ }^{3}$ Celebrizadas pelas redes sociais da Internet, elas a empregam para promover gostos e tendências, e com isso acabam criando objetos de desejo para quem as segue e consequentemente gerando consumo e mais valia para as marcas que as utilizam como "embaixadoras" - já que muitas vezes a publicidade é feita de modo camuflado, como trataremos a seguir.

O objetivo deste pequeno artigo é compreender a figura da influenciadora digital e as complexidades das operações de poder, legitimação, subordinação e dominação que ocorrem na tríade indústria, influenciadoras e consumidores. Ao longo deste texto investigaremos como seus seguidores recebem, entendem e classificam a informação de moda. Como estas pessoas, presentes apenas nos meios digitais se tornam tão importantes na dissipação de um habitus de vestir, que se tornam "celebridades" dignas de primeira fila de desfiles de grandes marcas internacionais. Diferente da maior parte dos consumidores, que não analisaram criticamente o fenômeno, não nos perguntamos o que as grandes marcas observam nestas mulheres ao ponto de pagá-las para que usem seus produtos, mas sim o que as marcas observam no mercado com o qual elas dialogam e que serão consumidores em potencial; como verificamos, as influenciadoras são apenas uma ponte que liga a indústria de moda ao consumidor, isto é, instâncias de legitimação de arbitrários culturais para produção do mais valor.

\section{O que são digital influencers?}

Digital influencers são anônimas ou pessoas já conhecidas que usam plataformas digitais ${ }^{4}$ para se comunicar com os seus seguidores e mostrar seu estilo de vida e hábitos diários. Falando especificamente sobre plataforma digital do Instagram, para qual dirigimos este pequeno estudo. Muitos tentam garantir seu espaço como influenciadores digitais, mas apenas alguns conseguem de fato ser legitimados ${ }^{5}$ e, portanto, reconhecidos como tal. Atuando como agentes do meio, influenciadores são uma peça da engrenagem da estrutura capitalista, ajudam a alcançar um determinado fim - a venda ou a produção da mais valia - e são facilmente substituíveis quando a indústria não os considera mais aptos para essa função. Afinal, ser um influenciador "[...] não

\footnotetext{
${ }^{1}$ Aqui nos referimos a grandes marcas internacionais e renomadas de moda como Chanel, Dior, Gucci etc.

${ }^{2} \mathrm{O}$ Instagram é uma rede social online para compartilhamento de imagens e vídeos criada em 2010.

${ }^{3}$ Influenciadoras digitais, em português.

${ }^{4}$ Plataformas digitais como o Instagram, blogs, Youtube etc.

${ }^{5}$ Sobre as formas de legitimação das digital influencers, falaremos no capítulo subsequente.
} 
consiste meramente em possuir os atributos necessários, mas também em manter os padrões de conduta e aparência que o grupo social do indivíduo associa a ela" (GOFFMAN, 1985: 74), tal como na área dos esportes, quando um jogador de futebol ou um lutador de MMA já ofereceu tudo aquilo que poderia oferecer, em razão da idade ou de uma contusão grave, ele é afastado sem função social. Quando um digital influencer não se está mais no padrão esperado, é quase certo que seja substituído.

Consideramos que para o entendimento de quem são estas pessoas, devemos utilizar a noção de microcelebridades (BRAGA, 2008). Microcelebridades são pessoas das mais diversas profissões e idades, que alcançam um grande valor simbólico devido ao que apresentam nas redes sociais e que por conta dessa consagração, acabam ficando conhecidas neste espaço, por esse determinado público. Verifica-se também que podem ser completamente desconhecidas por outros grupos sociais. Esse dado é importante, pois evidencia que estas pessoas são muito conhecidas apenas para um determinado público, mas que para outros não são ninguém, ou seja, conseguimos comprovar duas coisas i) o quanto as digital influencers trabalham para públicos diferentes e ii) que por essa razão "atendem" isso que os profissionais de marketing denominam nichos de mercado ${ }^{6}$ diferentes. A sociedade industrial se caracteriza pela sua divisão em classes ou grupos sociais, consequentemente, temos vários nichos de mercado. Contemporaneamente, no estágio em que nos encontramos, pode-se afirmar que vivemos em uma sociedade de classes com valores culturais sem uma unidade, mas fragmentados. Assim, os públicos se tornaram cada vez mais segmentados por ideologias, valores, gostos e estilos de vida (CASTELLS, 1999: 425) e, do mesmo modo, influenciadores são divididos em alguns nichos, de acordo com o que fazem moda, fitness, gourmet etc. - e também com as classes ou grupos sociais para os quais se dirigem. Os publicitários e os profissionais de marketing encontram e recrutam pessoas específicas de cada grupo social, que sejam representantes de uma forma particular de anunciar o seu produto: só se anuncia um produto destinado à classe $A$; com influenciadores que dialogam com a classe $A$; só se anuncia um produto destinado à classe $C$, com influenciadores que dialogam com a classe $C$; e isto é uma manobra publicitária a favor da indústria. De forma geral, as influenciadoras digitais mulheres e que trabalham com moda (meu objeto de estudo) são remuneradas pela atividade de publicidade que exercem de duas maneiras diferentes: i) trocando suas "dicas" por presentes da marca, uma espécie de escambo ou ii) fazendo esta troca por dinheiro. É mais comum que haja troca financeira apenas com as influenciadoras que já possuem o selo de autenticidade ${ }^{7}$, que são aquelas que possuem maior número de seguidores e que, portanto, atingiram nível mais alto de reconhecimento ou consagração no grupo ou classe em que atuam.

Outra forma de distinção que diferencia as digital influencers reconhecidas e portanto com maior poder financeiro que as demais é a forma como empregam as imagens fotográficas. Enquanto as influenciadoras, com menos seguidores operam em troca de presentes (roupas e adornos), acabam recorrendo aos selfies ${ }^{8}$ e fotografias tiradas de um modo que poderíamos classificar de não profissional. Aquelas que têm retorno financeiro nesta profissão têm fotografias montadas e tiradas por fotógrafos profissionais. Além das fotografias feitas e tratadas por

\footnotetext{
${ }^{6}$ Nichos de mercado são públicos específicos dentro de um mercado maior, suas eventuais "necessidades" são analisadas e os publicitários utilizam destas informações para vender de forma mais eficaz um produto.

${ }^{7}$ Explicaremos mais adiante (parte 3 deste artigo) o que é um selo de autenticidade por entendermos que ele é uma das formas de legitimação das digital influencers.

${ }^{8}$ Selfies são uma espécie de autorretrato, onde o próprio fotografado se fotografa.
} 
fotógrafos profissionais, seus cabelos e maquiagem são feitos também por profissionais.

Muitos classificam as digital influencers como mulheres com "bom gosto" e que por isso ocupam lugar de destaque junto as marcas de moda. Para quem pensa o gosto de maneira idealista, como dom pessoal e individual garantido apenas para alguns poucos, percebemos que esta forma hegemônica de pensar acaba tornando as influencers pessoas "acima" das demais, ou seja, detentoras de um "je ne sais quoi" e por essa razão, passíveis de serem seguidas e copiadas, considerando seus dons carismáticos. É possível que até mesmo elas acreditem sinceramente em suas "encenações", afinal, não são cínicas (GOFFMAN, 1998: 25) quando consideram que estão "lançando" alguma tendência ou quando acham que seu gosto é mais bem apurado do que o da maioria. Daí nos perguntamos se elas se reconhecem como "funcionárias da indústria" ou no mínimo parceiras destas.

Para nós, que pensamos de maneira não idealista, é fácil observar que o gosto é na verdade um sentimento coletivo, resultante de construção social, de um habitus criado e aceito pelo grupo social ou a sociedade em que o indivíduo se encontra, mas fica difícil percebermos essas pessoas neste coletivo por elas terem acesso antes ao que será vendido nos meses subsequentes. Para o sociólogo francês Pierre Bourdieu, esse processo se chama violência simbólica e é a consequência de uma ação social coercitiva de inculcação de valores, para a imposição de um novo "sistema de preferências" (BOURDIEU, 1977: 22). As pessoas acabam agindo e se vestindo de forma semelhante, enfim, tendo o mesmo gosto, por conta de um automatismo inconsciente, de um processo de coerção naturalizado. Talvez não consigamos perceber que o gosto é algo inculcado, pois ele acaba sendo naturalizado não por ter sido falado para nós, e sim por estarmos vendo aquele tipo de roupa em pessoas de nosso grupo social ou em suportes midiáticos que temos acesso (TV, Internet, revistas etc.). As mudanças de gosto são determinadas por circunstâncias externas à subjetividade ou individualidade das pessoas. É através da dinâmica econômica e pela sociedade e não como muitos pensam, definidas por determinações metafísicas ou aspectos subjetivos, como manda boa parte da estética moderna.

Falando em economia, gostaríamos de ressaltar que as influencers são fruto da indústria de moda e trabalham para ela; e citando Bourdieu, podemos dizer que estas mulheres ocupam mais ou menos o lugar dos marchands de tableaux no Campo da Arte, já que têm uma posição estratégica no comércio das roupas e acessórios, tal como os marchands tinham ou têm no comércio de obras de arte. Elas produzem a associação necessária entre o designer do Campo da Moda, ou do artista/estilista do Campo da Arte, com os compradores. Elas trabalham para a indústria da moda, são responsáveis por reproduzir e ampliar, isto é, legitimar ou consagrar as novas peças, a dita "nova tendência", para o grande público, que irá adquiri-la. O seu eventual "bom gosto" é, na verdade, nada mais nada menos do que o que a indústria pretende que se consuma nas próximas estações. Pode até parecer que estas mulheres lançam de fato tendências, mas com uma análise mais apurada conseguimos perceber que na verdade a indústria passa para elas as peças em primeira mão, pois é por meio delas que a nova voga ou tendência será transmitida para o grande público. $O$ gosto de influencers não é próprio, não pertence a uma pessoa dotada de um "dom" inato do "bom gosto", mas o reflexo daquilo que a indústria deseja vender. Não se trata de uma vocação ou fruto de dom divino ou qualquer tipo de preferência pessoal que por algum motivo poderá consagrar um determinado tipo de vestimenta ou adorno. Nos comportamos, socializamos e vestimos de acordo com a tradição de nosso grupo social, que requer esse comportamento, e não por qualquer individualidade (GOFFMAN, 1985: 15). 
Verificamos também que o público também costuma considerar que os produtores designers ou artistas/estilistas - por terem sido agraciados com a mesma noção passadista do "dom" ou do "bom gosto" inato, precisam dos seus arautos, ou seja, que as influencers são aquelas que começam a divulgar aos quatro ventos aquilo que está em voga primeiro que todos os outros, daí porque muitos julgam que elas possuem o mesmo "dom" dos criadores, pois teriam uma espécie de "faro" para o novo, tal como os artistas seriam as antenas do futuro e na verdade seu papel social é exatamente esse. Elas recebem as novidades da indústria em primeiro lugar, pois a partir do momento que elas as utilizam, acredita-se que as peças passam a ser "desejadas" por outras pessoas e acabam sendo adquiridas. É interessante para a indústria que elas advoguem a favor de uma tendência. É importante ressaltar que o lugar que elas ocupam na indústria - já comparado acima com o local do marchand de tableaux de Bourdieu - era ocupado anteriormente por modelos de revista e por atrizes, cantoras e demais celebridades. A indústria sempre dependeu de alguma instituição que exibisse suas novas peças, mas o que nos chama atenção nesse fenômeno das influencers é que hoje essa propaganda é feita por pessoas que não têm nenhum reconhecimento profissional em alguma atividade que lhes dê projeção social - não são, modelos, atrizes ou cantoras consagradas - e que não são conhecidas do grande circuito e nem apenas moradoras dos Estados Unidos e alguns poucos países da Europa. É por meio da propaganda feita por estas mulheres que uma nova voga se torna conhecida pelo público.

Percebemos que as mulheres que trabalham para o mesmo nicho de mercado, acabam se tornando muito parecidas, verificamos uma uniformização das denominadas "inovações" que pretendem legitimar, não só na forma de vestir, na forma de se fotografar, mas também na forma de se apresentar naquele ambiente digital - do qual trataremos adiante.

Se partirmos do pensamento do cientista social canadense Erving Goffman, um ator independente de acreditar em seu número ou de ser apenas cínico, faz o que faz por conta de um consenso operacional, adquirido junto a seu grupo social (GOFFMAN, 1985), as influencers se comportam como se comportam por conta de uma identidade estabelecida por todas elas. Perguntamo-nos até que ponto o mundo digital, nesse caso feito praticamente de imagens, não torna mais fácil a absorção deste tipo de conteúdo de moda sem que nos percebamos disto. Enfim, em que medida as imagens operam com mais eficácia a legitimação das vestimentas, acessórios e adornos?

\section{Formas de legitimação das digital influencers}

Julgamos que para refletir sobre esse fenômeno, devemos compreender como ocorre a legitimação destas pessoas. Conseguimos identificar algumas destas formas e a seguir trataremos um pouco de cada uma delas. Elas são legitimadas pelo público - através do número de seguidores e pelo selo de autenticidade ${ }^{9}$ do Instagram -, pelos pares - neste caso, outras

\footnotetext{
${ }^{9} \mathrm{O}$ selo de autenticidade é um símbolo oferecido pelo próprio aplicativo que tem como objetivo garantir a veracidade da conta de celebridades e marcas, uma marca azul que é colocada ao lado do nome nesta rede social. Acredito que a partir do momento em que este selo é oferecido, o seu status de "celebridade" é legitimado por uma instância maior e por isso o valor simbólico de suas escolhas de vestuário é visto como superior tanto pelas maisons de moda quanto pelo público.
} 
influencers e as marcas de moda (BRAGA, 2009), pela geografia (conceito que explicarmos logo a seguir) e também pela fotografia.

\section{Pelo público}

Sendo a cultura mediada pelos meios de comunicação, os novos sistemas de códigos são transformados pelo novo sistema tecnológico (CASTELLS, 1999: 414), a mídia digital fundamentalmente calcada nas imagens fotográficas do Instagram, de acordo com nosso entendimento, muda a relação das mulheres seguidoras de influencers com a moda e, consequentemente, afeta a forma como a consomem. Se antes precisávamos de revistas com matérias escritas, entrevistas com designers ou estilistas, opinião de setores industriais e celebridades, para observar as novas vogas de vestuário - suportes impressos e com matéria escrita -, hoje apenas as observamos mesmo sem perceber, por intermédio de fotografias destas mulheres, que além de nos mostrarem a novidade, algumas vezes ainda nos oferecem o link da loja online onde se pode adquiri-lo. A moda sempre foi passada pelas pessoas de forma empírica: usamos o que usamos por observar aquilo em outras pessoas, nas vitrines das lojas e no Brasil em meios de comunicação de massa como as novelas. Ocorre que a mídia impressa ainda fazia uso dos textos escritos e hoje eles praticamente inexistem.

Observamos por meio das interações de usuárias desta rede social com as influencers que, apesar de espacialmente separadas, as seguidoras acreditam ter algum vínculo afetivo com quem é seguido. Novamente voltamos a afirmar que tal como o seu smartphone é controlável e familiar, as mensagens de moda são absorvidas "tranquilamente" por quem as vê (CASTELLS, 1999: 422) e acabamos imaginando que aquelas mulheres são como nossas amigas, aquelas que seguimos na rede. Apesar de virtuais, essas comunidades funcionam em outro plano de realidade e têm a sua própria dinâmica (CASTELLS, 1999: 446), basicamente por intermédio de imagens. O processo real de comunicação depende da interação entre o emissor e o receptor na interpretação da mensagem (CASTELLS, 1999: 420), portanto é importante que o produto, a influencer e o público estejam a par dos mesmos códigos e símbolos para que a comunicação seja realizada o mais corretamente possível. Porém, apesar de todos os cuidados ao comunicar, devemos lembrar que existe uma assimetria no processo comunicacional: enquanto nós temos o controle daquilo que falamos, quem nos assiste têm controle do que foi falado com palavras e do que foi falado pelas nossas atitudes no momento da fala (se rimos, nos sentimos desconfortável etc.) (GOFFMAN, 1985: 16). Todos gerenciamos a impressão que queremos passar, e com as microcelebridades da internet, me parece que este gerenciamento é ainda maior, por conta do fato de que podemos vêlas e interpretar a sua hexis corporal, tal como podemos perceber objetivamente valores culturais por intermédio de textos escritos. Se o autor emprega frases vulgares, imediatamente temos os meios para classificá-lo como pertencente a esse ou aquele grupo social, pois essas formas verbais são concretizações de comportamentos sociais específicos e por isso podemos classificar alguém pela forma como ela formula suas frases. Pelas imagens também podemos ver objetivamente, mas de modo mais sutil ou talvez mais direto, qual seria a extração social do representado.

\section{Pelos pares}

O reconhecimento por parte de outras influenciadoras e pelas marcas de moda é de 
extrema importância para quem usa o Instagram como ferramenta de trabalho. Assim como a legitimação de uma obra de arte é dada pela instituição que a guarda (CIPINIUK, 2003: 58) tal como o museu ou os centros culturais. Uma pintura que está guardada no quatro de despejos da estação rodoviária de Paris, não possui a mesma legitimação do que uma pintura exposta, ou melhor, "guardada" no museu do Louvre, daí podemos afirmar que o que dá credibilidade para uma influenciadora é a marca (griffe) para qual opera. Uma influenciadora que frequenta desfiles e usa marcas internacionais de uma forma geral é mais bem posicionada ${ }^{10}$ no meio do que aquelas que não o fazem.

Ser reconhecida pelas demais influencers também é um diferencial de prestígio ou honradez. Algo muito recorrente nas publicações são os comentários, que, de forma geral, são respondidos rapidamente quando o elogio é tecido por algum par e ignorados solenemente quando feitos por pessoas comuns. $\mathrm{O}$ que as torna verdadeiras são os elogios vindos de fora, sejam espontâneos ou não, os comentários são importantes formas de mostrar poder (BURKE, 2009: 64).

\section{Pela geografia}

Quando falamos em influenciadoras digitais, outro ponto importante na legitimação é a geografia. Lugares que frequentam são tão importantes quanto as roupas que vestem, desfiles de moda em capitais europeias, restaurantes sofisticados e hotéis caríssimos fazem parte do pacote para que se mostre seu poder tanto de influência no público que a segue quanto seu capital econômico e simbólico adquirido. Além disso e mais uma vez, reais ou imaginados, closets luxuosos são indispensáveis para mostrar poder e distinção.

\section{Pela imagem fotográfica}

Fazendo uma análise das influenciadoras brasileiras com selo de autenticidade e que atuam no Campo da Moda percebemos que por serem direcionadas para isso que se chama um mesmo "nicho de mercado", elas acabam adotando posturas, formas de vestir e de fotografar semelhantes - assim como em qualquer grupo social, somos semelhantes aos nossos pares. Somos socialmente moldados para nos ajustar às expectativas da sociedade em que nos apresentamos (GOFFMAN, 1985: 40).

Quanto à forma de fotografar, as poses são bastante semelhantes. Mesmo que mesclem em seus perfis fotos de algo que poderíamos chamar de naturalidade. Também convencionais, elas são bastante artificiais e nota-se que são pensadas antes de serem fotografadas de fato. Algumas poses e posturas são marcantes: olhar para baixo, "ajeitar" os cabelos e atravessar uma rua sem carros, parecem ser poses bastante usadas por elas.

A estandardização de poses e expressões se fez bastante necessária no caso de imperadores e reis (CIPINIUK, 2003: 43), como estes tinham seus retratos exibidos em diversas residências e repartições públicas do país, deveria haver um padrão nas representações para que fossem reconhecidas por quem as via. Podemos dizer que a representação em posturas iguais

\footnotetext{
${ }^{10}$ Neste caso, ser mais "bem posicionado" é ser privilegiado por operar para uma marca que é reconhecida internacionalmente.
} 
(como no caso dos monarcas) e em meios de representação e molduras semelhantes (como no caso da Santa Casa da Misericórdia do Rio de Janeiro (CIPINIUK, 2003: 51) oferecem noção de que de fato o representado ocupa o local que ele tem no retrato, já que além de mostrar quem é esta pessoa na sociedade, dá unidade para aquilo que é visto. Assim como monarcas, as influenciadoras têm uma maneira ou forma de se retratar, uma hexis corporal, maneira essa que as identificam como tal, mesmo quando alguém que não as conhece vê a fotografia. É um código que varia de sociedade para sociedade, de período para período, pois cada sociedade e época tem seus próprios códigos (CIPINIUK, 2003: 60). Quem fotografa, quem é fotografado e quem vê a fotografia estão no mesmo contexto, para que haja entendimento daquilo que está sendo representado é necessário que empreguem o mesmo código formal.

Quem fotografa e quem é fotografado usa enquadramentos, poses, ambientes e objetos conscientemente para indicar uma posição social (CIPINIUK, 2003: 67-68), enfim, reproduzem o mesmo modus operandi. Assim como o público do século XVII não se importava com os clichês - a audiência conhecia as convenções e não se importava em vê-las em prática (BURKE, 2009: 31) hoje também parecemos não nos importar. Poses sempre iguais de digital influencers parecem não nos incomodar, pelo contrário, parece que nos sentimos amparados por aquilo, tal qual o público do século XVII, conhecemos as convenções e nelas moldamos nossas expectativas (BURKE, 2009: 31). É normal vermos algum influenciador com certa pose, mas tratamos com deboche quando vemos alguém do nosso meio, sem fama, fazendo-a. Se a pequena burguesia passou a se retratar e expor os retratos tal como os barões do café faziam nas suas salas de visita (CIPINIUK, 2003: 50), porque acharíamos que a classe média deixaria de querer se retratar como os "comanditários da moda"? Se em épocas anteriores o espaço em que essas imagens eram exibidas, consistia também como parte do sistema de valorização do retratado (CIPINIUK, 2003: 58), hoje, especialmente na internet, o espaço de exibição é dividido entre "celebridades" e anônimos populares. Por conta do número de seguidores e consequentemente o número de visualizações que cada fotografia possui, não podemos dizer que ambos ocupam a mesma "classe" social, mas ambos estão no mesmo espaço digital. Se antes era o lugar de exibição, o consistório das igrejas de irmandades, assim como junto aos objetos que cercavam o retratado que se conjugavam para dar legitimidade ao retratado, pois esses espaços e objetos ofereciam credibilidade à figura do retratado, hoje, no caso das influencers de moda, tanto quanto os objetos que as cercam quanto a marca para a qual operam, têm esse papel.

Todas as convenções sociais que podemos ver nas imagens são escolhas arbitrárias construídas por determinações coletivas (CIPINIUK, 2003: 89) e as representações de retratos são um bom exemplo disto. As maneiras ou modos de representar em diferentes períodos históricos são convenções que formam a percepção e representação das coisas do mundo (CIPINIUK, 2003: 89). Por meio delas ficou convencionado uma maneira de ser (raison d'être) de certa classe social. Sendo assim, um grupo social ao definir seus princípios e valores estéticos, influenciam a definição da personalidade e do chamado gosto de cada pessoa do grupo (CIPINIUK, 2003: 99). De modo geral o senso comum pensa que a personalidade e o gosto são individuais, mas defendemos que estes são inculcados pelo coletivo, assim como a forma de representar.

\section{A comunicação de moda mediada por computadores e a indústria}


A comunicação mediada por computador $(\mathrm{CMC})$ e realizada no ambiente online é um fenômeno social novo, este tipo de comunicação reforça a coesão social e, especialmente gera um novo grupo de excluídos, uma vez que aqueles que não têm acesso ao computador e à internet, tornam-se imediatamente segregados, excluídos socialmente. Este novo suporte de comunicação acaba transformando radicalmente o espaço e o tempo, dimensões fundamentais para a vida humana (CASTELLS, 1999: 463), uma vez que por meio dele conseguimos nos comunicar em tempo real com pessoas distantes fisicamente de nós e em outros fusos-horários. Fazemos o que somos socialmente programados para fazer, portanto, as influenciadoras cumprem seu papel social ao nos incutirem o desejo de consumir novas peças de vestuário e adornos. O interessante da CMC é que ela não substitui outros meios de comunicação, ela apenas reforça os padrões sociais preexistentes (CASTELLS, 1999: 449), a propaganda sempre existiu, mas com o Instagram e as influencers as propagandas apenas mudaram de mídia, deixaram de estar presentes apenas nas revistas impressas, telas de cinema e televisão e passaram a estar presentes em nossas redes sociais.

O desenvolvimento dos meios técnicos do Instagram fez com que todos que participam dele pudessem pensar que possuem o controle da mídia, uma vez que podem colocar seus looks e ideias na rede. Assim, ao contrário da televisão, os consumidores de internet supõem que também são produtores de conteúdo (CASTELLS, 1999: 439) e não apenas espectadores. Apesar de uma parte considerável da comunicação mediada por computadores ser espontânea e não organizada (CASTELLS, 1999: 439) e da arquitetura da rede ser aberta do ponto de vista tecnológico (WU, 2012: 328), o público não especializado utiliza o que é socialmente programado para usar, acreditando que domina o suporte eletrônico. Temos outras formas de fazer pesquisa, mas o Google parece ser sempre uma ferramenta mais prática e acessível do que uma biblioteca para o público geral; podemos enviar cartas, mas os e-mails são mais rápidos e enviam sua informação aparentemente de graça e para qualquer lugar do mundo onde haja conexão com a internet; com os jornais online somos levados a crer que conseguimos acessar notícias de quase todos os países do mundo e de nossa própria cidade sem nos preocuparmos em ir até a banca de jornais; com a informação de moda não é diferente, já não é só por meio de revistas especializadas e anúncios publicitários que sabemos o que foi lançado na última Fashion Week. Consideramos importante mostrar como a internet modificou nosso jeito de conseguir informação e de nos comunicar, para que cheguemos até o Instagram, que é hoje uma das plataformas utilizadas por marcas de moda para gerar desejo por suas novas peças. É sempre bom salientar que não somos obrigados a utilizar redes sociais e nos comunicar por computadores, mas nos parece que a utilização destes, principalmente pelo público jovem, tem muito a ver com a interação social que, apesar de não deixar de existir no meio físico, passa a ocorrer de forma massiva pelo meio digital; a difusão em larga escala da internet só se deu por conta das pessoas, que passaram a utilizá-la (WU, 2012: 340). A própria sociedade nos obriga a utilizar estes meios para nos comunicarmos, se a interação é uma influência recíproca dos indivíduos sobre as ações uns dos outros (GOFFMAN, 1985: 23), conseguimos observar que a partir do momento que uma "nova" forma de comunicar passa a ser utilizada por grande parte dos grupos sociais, comumente a outra a segue e passa a utilizar também.

Com este novo suporte de mídia implantado, foi estabelecido um novo tipo de comunicação e consequentemente uma nova forma de consumo de moda, que apesar de se pautar em um modelo de negócio e de propaganda já existentes - a publicidade por imagem fotográfica com objetivo de gerar venda ou mais valia - faz a sua publicidade de uma forma diferente. Acreditamos 
que com seus produtos expostos não apenas na mídia impressa da revista especializada em moda e também aquela que emprega imagens fotográficas com modelos profissionais, a propaganda do produto é mais bem-feita. Tendemos a considerar que as influencers são pessoas comuns, e não microcelebridades do meio digital que atuam diretamente ligadas à indústria de moda. Imaginamos que muito disso tem a ver com o fato delas estarem em nosso smartphone e rede social, locais que nós achamos que é privado (CASTELLS, 1999: 422) e "misturadas" a pessoas que de fato conhecemos e levam vidas comuns. Ao rolar o feed, vemos a publicidade destas marcas por meio das \#publipost ${ }^{11}$ das influenciadoras no mesmo local que vemos fotos de nossos amigos e por isso acabamos as colocando no mesmo "patamar", é como se o novo must have da estação estivesse sendo mostrado por alguém comum, por algum conhecido, e não por uma modelo paga por uma empresa de moda. Por trás de cada venda de moda, há alguma mídia que fez com que desejássemos aquilo; diferentemente dos figurinos de novela, que "criam o desejo" por aquilo sem que se mostre onde foi adquirido; no Instagram a publicidade não pode ser escondida, mas mesmo "tagueada"12 com a \#publipost, continuamos a não perceber como ela opera. Seguir uma destas influenciadoras, acaba produzindo uma conexão, um laço de intimidade com ela; a dica de compra parece estar sendo passada por uma amiga, por alguém de nosso convívio social.

Julgamos que não devemos considerar o Instagram - ou outro meio de comunicação - como neutro e com efeito desprezível. A mensagem de moda é enviada da mesma forma para todos os que veem as publicações destas mulheres, mas para ser completamente entendida, a mensagem terá que passar pelo contexto social em que o indivíduo que a vê vive (CASTELLS, 1999: 421), sendo mais efetiva para o público a que foi destinada. A indústria por meio destas mulheres faz propaganda sem de fato dizer que a está fazendo, é uma forma menos "rígida" de mostrar seu produto, uma forma de delegar a propaganda para terceiros (GOFFMAN, 1985: 39) e se mostrar menos preocupado - ou mais blasé - com isso: não somos nós que mostramos nossos produtos, são as digital influencers.

Acreditamos que as "dicas" oferecidas por elas são de fato dicas de uma amiga, sem de fato parar para pensar que quando nos apresentamos para outras pessoas nossas atividades têm caráter promissor (GOFFMAN, 1985: 12). Tendemos a achar que encenamos pouco, como atores sociais temos pouca consciência dos padrões que irrefletidamente utilizamos (GOFFMAN, 1985: 57), achamos que somos o que somos por vontade própria e não por uma arbitrariedade social. Por não termos consciência de que atuamos o todo tempo, tanto nós quanto as influencers somos sinceros na apresentação de nosso número (GOFFMAN, 1985: 25), elas são sinceras quando acreditam que dão dicas por conta própria (sem a intervenção da indústria) e nós somos sinceros quando levamos em conta que elas trabalham por si próprias na defesa de um gosto pessoal. Voltamos a ressaltar que o público - pelas razões já apontadas acima - costuma considerar que por terem sido agraciadas com o "dom" do bom gosto, as influencers começam a usar uma voga primeiro e não por ser esse seu papel.

\footnotetext{
${ }^{11}$ O é \#publipost é uma determinação do Código de Defesa do Consumidor que ordena "A publicidade deve ser veiculada de tal forma que o consumidor, fácil e imediatamente, a identifique como tal", no caso das influencers, a não utilização deste termo é passível de multa aplicada pelo Conar (Conselho Nacional de Auto-regulamentação Publicitária).

${ }^{12}$ Uma tag é uma forma de organizar informação na internet. Quando uma \#publipost é marcada em uma imagem de influencer e clicamos em cima dela, temos acesso a todos os \#publipost já utilizados no Instagram.
} 


\section{Considerações finais}

Finalizamos este artigo salientando que estamos diante de um fenômeno de moda que não deve ser negligenciado e não pode ser tratado como mera futilidade. É importante pensar o papel do campo midiático digital na moda, pois se a compreensão das identidades sociais é também passada pelas mídias, é inegável que uma plataforma como o Instagram, é uma forma de comprovar o que um grupo social veste e vive no momento. Para que não pensemos que as influenciadoras são o que são por elas mesmas ou por obra do acaso, é importante que saibamos as identificar e identificar suas formas de publicidade e para isso consideramos fundamental estarmos cientes das formas que elas usam para se legitimar.

A moda sempre dependeu do ver e do ser visto, do exibir-se ao olhar do outro e de certa forma por se considerar que podemos reproduzir a distinção social por vestimentas e adornos; mas nos parece que estes fatos nunca foram tão importantes quanto hoje. Mimetizamos comportamentos, falas e gostos - de pessoas que acompanhamos pela internet, aprendemos melhores poses para fotografias, melhores ângulos para selfies, melhores exercícios para uma barriga sem dobrinhas. Mas continuamos sem saber se realmente "aprendemos" tais coisas: se a cópia é feita subjetivamente ou se realmente pensamos sobre aquilo que estamos fazendo, afinal, quem absorve sem perceber tais comportamentos e quem os copia? Se partirmos do pensamento de Erving Goffman, um ator independente de acreditar em seu número ou de se comportar de modo cínico, fazer o que faz por conta de um consenso operacional, adquirido junto ao seu grupo social (GOFFMAN, 1985).

Acreditamos que só o fato de vermos pessoas comuns se comportando tal qual estas mulheres, já nos comprova o quanto elas estão modificando nossa forma de consumir. Modificamos nosso meio de conseguir informação de moda, modificamos nossa experiência de compra e como trabalhadores do segmento, vemos que os meios de produzir, expor e vender foram transformados. Embora as celebridades da mídia e o e-commerce sejam modalidades de ações humanas, ambas são exemplos de como operam com o mesmo suporte midiático e não faltam no mercado brasileiro nem no internacional mais exemplos de como as novas mídias vêm alterando a produção, recepção e circulação de mercadorias de moda. Um fenômeno desse porte e que altere de forma tão brusca um grupo social e modifique a dinâmica de mercado não pode ser ignorado por cientistas sociais, precisamos que alguém volte os olhos para as influenciadoras digitais, sua ligação com a indústria e como seus seguidores são afetados. Um novo padrão de consumo foi estabelecido e enquanto designers, precisamos compreender e repensar como os consumidores lidam com a moda.

\section{Referências}

BRAGA, Adriana A. Microcelebridades: entre meios digitais e massivos. Revista Contrampo. Niterói, número 21, agosto de 2010. p. 40-53. 
. Personas Materno-Eletrônicas: feminilidade e interação no blog Mothern. Porto Alegre: Sulina, 2008.

. "Todo mundo pode ter blog? Práticas de legitimação na blogsfera". In.: RODRIGUES, C. (Org.). Jornalismo On-line: modos de fazer. Rio de Janeiro/ Porto Alegre: Editora PUC-Rio/Sulina, 2009.

BOURDIEU, Pierre. A produção da crença: contribuição para uma economia dos bens simbólicos. São Paulo: Zouk, 2004, p 17-111.

. Razões Práticas: Sobre a teoria da ação. Campinas, SP: Papirus, 2011.

CASTELLS, Manuel. A cultura da virtualidade real. In: Sociedade em Rede - A Era da Informação: economia, sociedade e cultura. São Paulo, Paz e Terra, 1999, p. 412-466.

. Conclusão: a sociedade em rede. In: Sociedade em Rede - A Era da Informação: economia, sociedade e cultura. São Paulo, Paz e Terra, 1999, p. 565-574.

CIPINIUK, Alberto. A face pintada em pano de linho: moldura simbólica da identidade brasileira. Rio de Janeiro: Ed. PUC-Rio; São Paulo: Loyola, 2003.

. O campo do design e a crise do monopólio da crença. São Paulo: Blucher, 2017.

DEBRAY, Régis. Vida e morte da imagem. Petrópolis, 1993.

GOFFMAN, Erving. Introdução/Representações. In.: A Representação do Eu na Vida Cotidiana. Petrópolis, Vozes, 1998, p. 11-75.

LIPOVETSKY, Gilles. O império do Efêmero - A moda e seus destinos nas sociedades modernas. São Paulo: Companhia das Letras, 2009.

SENNET, Richard. O declínio do homem público: as tiranias da intimidade. Rio de Janeiro: Record, 2016.

SIMMEL, Georg. Filosofia da Moda. Lisboa: Edições Texto \& Grafia, 2014.

WU, Tim. A internet contra todos. In.: Impérios da Comunicação: do telefone à internet, da AT\&T ao Google. Rio de Janeiro, Zahar, 2012, p. 307-384. 